\title{
Use of Evidence-Based Herbal Medicines for Patients with Functional Gastrointestinal Disorders: A Conceptional Framework for Risk-Benefit Assessment and Regulatory Approaches
}

\author{
Gerald Holtmann ${ }^{\mathrm{a}, \mathrm{b}}$ Dietmar Schrenk ${ }^{\mathrm{c}}$ Ahmed Madisch ${ }^{\mathrm{d}}$ Hans D. Allescher ${ }^{\mathrm{e}}$ \\ Gudrun Ulrich-Merzenich ${ }^{f}$ Fermin Mearing ${ }^{g}$ Dominique Larrey ${ }^{h}$ \\ Peter Malfertheiner ${ }^{i}$

\begin{abstract}
a Department of Gastroenterology and Hepatology, Princess Alexandra Hospital, Woolloongabba, QLD, Australia;
${ }^{b}$ Faculty of Medicine and Faculty of Health and Behavioural Sciences, University of Queensland, Brisbane, QLD, Australia; ${ }^{c}$ Department of Food Chemistry and Toxicology, University of Kaiserslautern, Kaiserslautern, Germany; ${ }^{d}$ KRH Klinikum Siloah, Hannover, Germany; ${ }^{e}$ Klinikum Garmisch-Partenkirchen, Munich, Germany; ${ }^{f}$ Medical Clinic III, University Hospital Bonn, University of Bonn, Bonn, Germany; ${ }^{9}$ Servicio Aparato Digestivo, Centro Médico Teknon, C/Vilana s/n, Barcelona, Spain; ${ }^{h}$ Hépatogastroentérologie Hopital, Montpellier, France; 'LMU Klinikum der Universität, Medizinische Klinik II, Munich, Germany
\end{abstract}

\section{Keywords}

Herbal therapies · Functional gastrointestinal disorders .

Registration · Risk-benefit-analysis

\begin{abstract}
Background: Herbal or complementary medicines are frequently used for the treatment of patients with functional gastrointestinal disorders (FGID). Regulatory requirements for herbal therapies are inconsistent and, in many jurisdictions, herbal therapies are either self-, minimally- or unregulated. Aim: To provide guidance for the appropriate and safe use of herbal medicines in patients with FGID patients with special consideration of the regulatory frameworks. Methods: A PubMed search of the literature was performed; relevant articles were included. Results: Similar to chemically defined therapies herbal medicines can cause adverse events. Thus, a risk-benefit appraisal should be undertaken for these therapies. While there is no disease specific mortality in FGID
\end{abstract}

patients, patients with FGID who fail to respond to "empiric" chemically defined therapies undergo diagnostic and therapeutic measures that can be associated with appreciable morbidity and mortality. Thus, effective herbal treatments that subsequently reduce health-care utilization, reduce risks related to diagnostic or therapeutic measures that are initiated if no improvement of symptoms occurs. This "protective" effect of effective treatments for FGID needs to be taken in consideration when the risks and benefits of treatments are determined. In addition, standards that mirror regulations for chemically defined treatments should apply and the components of the respective preparations should undergo ongoing toxicological testing and rigorous quality assurance measures (including pharmacovigilance) applied. Conclusions: Some herbal therapies offer significant benefits for patients with FGID. To ensure the safety of these treatments, the regulatory requirements should mirror requirements for chemically defined treatments.

(c) 2019 The Author(s)

Published by S. Karger AG, Basel

\begin{tabular}{ll}
\hline KARGER & $\begin{array}{l}\text { ( } 2019 \text { The Author(s) } \\
\text { Published by S. Karger AG, Basel }\end{array}$ \\
karger@karger.com & This article is licensed under the Creative Commons Attribution- \\
www.karger.com/ddi & $\begin{array}{l}\text { NonCommercial-NoDerivatives 4.0 International License (CC BY- } \\
\text { NC-ND) (http://www.karger.com/Services/OpenAccessLicense). } \\
\text { Usage and distribution for commercial purposes as well as any dis- } \\
\text { tribution of modified material requires written permission. }\end{array}$
\end{tabular}

Gerald Holtmann

Department of Gastroenterology and Hepatology, Princess Alexandra Hospital Brisbane Faculty of Medicine and Faculty of Health and Behavioural Sciences

University of Queensland, 199 Ipswich Road, Woolloongabba, QLD 4102 (Australia)

E-Mail g.holtmann@uq.edu.au 


\section{Introduction}

Chronic or relapsing gastrointestinal (GI) symptoms including abdominal pain, nausea, diarrhea, or constipation affect approximately one-third of the population in Western countries $[1,2]$. In $50 \%$ of cases, symptoms are severe enough to require a consultation with a General Practitioner or other health-care providers for diagnostic and therapeutic purposes [3, 4], and it is estimated that $>50 \%$ of these patients are ultimately referred to a specialist [5]. In $>50 \%$ of patients, symptoms remain "medically unexplained" after diagnostic work-up and are referred to as functional GI disorders (FGID). Patients with FGID are currently categorized based upon their GI symptoms according to the Rome criteria [6] into groups such as the irritable bowel syndrome (IBS) or functional dyspepsia (FD) [6]. Applying Rome-criteria in well-controlled trials, the gain over placebo for the available pharmacotherapies is very disappointing and rarely exceeds $10-15 \%[7,8]$. This might be partly explained by the heterogeneity of underlying causes of symptoms (including systemic inflammation [9], sensory or motor dysfunction [10], dietary [11] and psychologic factors [12]), and subsequently there is considerable overlap of categories [13-16] that is in particular evident in patients with severe disease manifestations [17]. Thus, a variety of factors can - in isolation or collectively - determine the manifestation and severity of GI and concomitant extraintestinal symptoms.

In primary care, treatment is usually initiated without comprehensive diagnostic work-up when the a priori likelihood of a structural cause for symptoms is low [18, 19]. Treatment may follow a trial-and-error approach and when initial interventions have failed [20]. Diagnostic approaches are initiated after failure to respond to one or more pharmacotherapies. Thus, the availability of treatments with proven efficacy is likely to reduce the need for comprehensive diagnostic work-up in FGID patients with a priori low risk of structural lesions as the cause of symptoms.

In many countries, herbal medicinal products are part of the routine treatment approach and reflected in the respective national treatment guidelines [21]. This is based upon evidence from a number of prospective, placebocontrolled clinical trials and subsequent systematic reviews and meta-analysis [22-28].

It is becoming increasingly important to include patient preferences into the individualized treatment plan. Indeed, one large population-based study revealed that $>20 \%$ of population-based subjects with suspected FGID had sought alternative health care for the treatment of their GI symptoms [29]. In a Canadian cohort, $60 \%$ of patients with inflammatory bowel disorders sought alternative or complementary medicines [30]. Thus, it is obvious that many patients with FGID or other GI disorders will use herbal therapies. On the other hand, criteria for the assessment of herbal medicines for the treatment of patients with GI disease, and the required risk-benefit assessment, are poorly defined.

There is an obvious unmet need for safe and effective treatment for patients with FGID. In this setting, patients frequently utilize herbal medicine to control their symptoms. While there is some evidence that specific herbal preparations are beneficial, there is the lack of a cohesive approach to assess the benefits and risks of herbal treatments for these patients. This review aims to provide guidance for the appropriate and safe use of herbal medicines for the treatment of patients with special consideration of the required regulatory frameworks.

\section{Material and Methods}

A PubMed search was conducted utilizing the MeSH search terms "complementary medicines," "herbals," "functional gastrointestinal disorders," "irritable bowel syndrome," and "adverse events." In addition, the references of relevant publications were screened for further publications (snowball technique).

\section{Burden of Disease}

Overall, FGID are the most frequent GI disorders causing GP consultations or referrals to specialists $[3,4$, 31] and can severely impact the quality of life [32], as many patients report extraintestinal symptoms such as anxiety, depression, sleep disorders, and fatigue [11]. The cost besides substantial workdays lost $[33,34]$, including health-care costs, that are on average USD $>2,000$ /year higher as compared to age- and gendermatched controls [35]. This is due to excess health-care utilization including emergency department presentations and diagnostic work-up with (repeat) endoscopic services, initiated due to the poor response to ineffective existing treatments. However, frequently the relevance of FGID is underestimated compared with many other conditions as they are not reflected in mortality statistics. This bias toward "hard measures of disease impact" such as mortality is understandable; data on cancer mortality clearly attract much more attention from the 
public and policy makers. However, the frequently chronic or relapsing nature of FGIDs cause disabilities in predominately young people and are a considerable burden to society even though life expectancy is not affected.

\section{Risk Associated with FGID: Diagnostic Work-up, Treatment, and Risk Due to Increased Utilization of Surgical Procedures}

While many clinical guidelines propose a trial-anderror empiric treatment approach and a comprehensive diagnostic assessment when the initial treatment has failed or symptoms relapse [19], both treatment and the diagnostic work-up (e.g., endoscopic procedures or cross-sectional imaging) may expose patients to potential risks. While the risk associated with cross-sectional imaging might be difficult to quantitate since the adverse effects due to the exposure to radiation will materialize years or even decades later, there are good data to quantitate adverse effects associated with endoscopic procedures. A recent study [36] that analyzed 263,426 endoscopic procedures revealed that 40 cases $(0.015 \%)$ required cardiopulmonary resuscitations and in approximately $1 \%$ of procedures an unscheduled emergency department visits and/or hospital admissions were required after the procedure [37]. Despite efforts to resuscitate, 18 patients (45\%) died. Perforations are another typical complication of colonoscopy. A study from the University Hospital Erlangen [38] observed in a cohort of 7,535 examinations (4,830 diagnostic and 2,705 therapeutic) a total of $25(0.33 \%)$ perforations and $2(0.026 \%)$ procedure-related deaths. Seven $(0.14 \%)$ perforations occurred during a diagnostic procedure and $18(0.67 \%)$ occurred during a therapeutic procedure. Three $(12 \%)$ patients were treated conservatively and $22(88 \%)$ required surgery. Thus, diagnostic measures used to rule out structural causes of symptoms in patients with suspected FGID are associated with appreciable morbidity and mortality. In the clinical setting, cross-sectional imaging including abdominal computed tomography is frequently used. If we assume a dose of 8-10 mSv [39] for a single abdominal computed tomography, this single diagnostic test may be associated with an approximately risk of a fatal cancer of 1 in 2,000 (https://www.fda.gov/radiation-emittingproducts/radiationemittingproductsand procedures/ medicalimaging/medicalx-rays/ucm 1 15329.htm). Thus, patients with FGID are exposed to a substantial

Regulatory Approaches for Herbal Medicines in FGID risk associated with the diagnostic measures that are initiated in selected patients. However, failure to respond to therapy is an important factor that triggers diagnostic measures.

Besides excess utilization of (endoscopic or radiologic) diagnostic procedures, subjects with physician-diagnosed IBS have significantly higher rates of appendectomies, cholecystectomies, hysterectomies, and back surgery than subjects without IBS [40] and outcomes in IBS patients appear to be poor [41]. Thus, failure to respond to a given therapy and subsequent use of diagnostic measures or even surgical interventions may expose patients to an appreciable risk.

\section{Treatment Options for FGID}

While FGID can be suspected or even diagnosed based upon the clinical presentation, it is a common practice to exclude organic disease if patients have not responded to an initial treatment targeting symptoms. Many guidelines also recommend Helicobacter pylori eradication as a first-line treatment approach in cases of dyspepsia [42]. A variety of lifestyle modifications or pharmacotherapies are well established and regularly used for the treatment of FGID. However, a significant proportion if not the majority of patient do not sufficiently respond to these measures, and there is a (striking) lack of efficient pharmacotherapies that provide relief to the majority of patients [43]. Similarly, dietary [44] and psychological interventions [45] (while superior to control interventions) [44] are effective in a relatively small proportions of patients.

\section{Treatment of FGID with Herbal Medications}

While typical pharmacotherapies target one underlying mechanism, some herbal medicines may offer advantages since they frequently contain a variety of active components that may target simultaneously different underlying pathways (e.g., motility and inflammation) [4648].

In the setting of multiple factors that - in isolation or collectively - cause the symptoms, multitarget therapeutics can be viewed as a reasonable treatment approach until treatments have become available that allow treatments that are individually tailored toward patients' needs with specifically compounded mixtures or bioactive constituents $[49,50]$. 


\section{A Historic and Regulatory Perspective of Herbal Medicines}

Plant extracts have been in use for centuries to treat common diseases [23]. For obvious reasons, precise mechanisms of the active compounds of extracts or definition of doses required to achieve clinical effects were poorly described or not characterized at all. Raw materials and subsequently the extracts used may be variable and affected by several conditions (soil, climate). Usually extracts from a single plant were given even though some medicines, such as traditional Chinese medicines or Japanese Kampo medicines, used combinations of plant extracts.

Even today medicine still uses therapies that were initially based upon specific compounds extracted from plants. Some of these plant extracts are the prototypes of drugs that are synthetically produced and widely used. Examples are acetylsalicylic acid with the naturally occurring anti-inflammatory precursors found in willow bark and meadowsweet or opiates initially found in poppies. In addition, there are now numerous industrially produced herbal products available that are based upon extracts from single or multiple plants. Unfortunately, the regulatory process for registration and approval of herbal medicines is highly variable across the various jurisdictions. There are multiple reasons for this variability; on the one hand, herbal medicines are traditionally used in some cultures and subsequently well accepted. On the other hand, herbal medicines are rarely studied scientifically and for many products data are insufficient to provide an accurate assessment of the quality, efficacy, and safety of most herbal medicines. Thus, there might be concerns not only regarding efficacy but equally concerns in relation to potentially harmful contaminations.

However, in some jurisdictions (e.g., in Germany), herbal medicines with proven clinical efficacy and safety are "authorized" in the same administrative process that is used for chemically defined drugs (e.g., STW-5), while other "traditional" herbal treatments without proven efficacy are "registered" only (e.g., some preparations with peppermint-oil). To ensure a continued safe and effective use following the marketing authorization, a pharmacovigilance system is in place and mandatory for both authorized and registered herbal medicines. While for "authorization" of herbal therapies pharmacologic, toxicologic and clinical efficacy data are required, it needs to be noted that in some jurisdictions herbal medicines are marketed as food or food additives with only minimal regulatory scrutiny. In these countries, it is frequently argued that the nature of plant extracts (and combinations of various plant extracts) may present an unsurmountable challenge for authorization. However, excluding herbal therapies from regulatory approval processes neither serves societies' nor patient's interests. The production of herbal medicines requires well-developed quality measures. This quality assurance is not only necessary to monitor the raw materials and the concentration of active ingredients but also requires to monitor and avoid contamination of the raw materials with pesticides, heavy metals, and mould toxins [51].

In the United States, herbal medicines are regulated by the Dietary Supplement Health and Education Act [52]. This act defines a dietary supplement as a vitamin, mineral, herb or other botanical, amino acid, or dietary substance to supplement the diet that may exist as a concentrate, metabolite, constituent, extract, or combination of ingredients. This statutory definition is unique for the United States. Manufacturers are entitled to market such products without registering them or requiring FD approval. Safety of the products is the sole responsibility of the manufacturer. In contrast, for chemically defined drugs the FD would require pharmaceutical companies to demonstrate that their drugs are effective and safe before market authorization is approved. Therefore, evidence in relation to clinical efficacy and safety has been generated for chemically defined medications. If herbal medicines are marked compliant with the Dietary Supplement Health and Education Act [52] or similar regulations, no efficacy and safety data are required, and skepticism of consumer and health professionals is warranted.

\section{Safety Assessment of Herbal Treatments}

In general - and similar to chemically defined medications - all herbal medicines therapies may cause adverse effects. This fact should trigger appropriate toxicology studies for herbal medicinal products to ensure that the respective preparation and their ingredients in the doses used do not expose patients to nonjustifiable risks. STW 5 (Iberogast ${ }^{\circledR}$ ) is an example of a herbal medicinal combination product containing 9 herbal extracts (Iberis amara [L.], Melissa officinalis [L.], Matric aria chamomilla [L.], Carum carvi [L.], Mentha piperita [L.], Glycyrrhiza glabra [L.], Angelica archangelica [L.], Silybum marianum [L.] Gaertn., and Chelidonium majus [L.]). This combination of extracts from a variety of plants has 
been tested in a variety of pharmacologic models on specific GI functions [53]. In addition, the efficacy of this herbal combination has been tested and confirmed in prospective, controlled clinical trials $[26,54,55]$, and tolerability has also been monitored and established in clinical studies as well as post-marketing studies. Available toxicology data for specific ingredients of STW5 do not provide evidence for relevant toxicity, neither in rodents such as rats [56, 57] nor mammalians such as pigs [58]. This seems to be in contrast to reports of hepatotoxicity for one of the ingredients, Chelidonium majus. It is of note that hepatotoxicity of Chelidonium majus is reported only with doses of Chelidonium alkaloids higher than $8 \mathrm{mg}$. Further studies revealed 2 alkaloids contained in Chelidonium with more pronounced liver toxicity: sanguinarine and chelerythrine. Toxicological studies in rats revealed difference between oral and parenteral administration of these substances. Oral intake of even high doses resulted in very low liver tissue levels of sanguinarine and chelerythrine, identified in in vitro studies as the most relevant greater celandine alkaloids [59-65]. In contrast, when applied intraperitoneally and thus bypassing intestinal absorption, sanguinarine in a dose of $10 \mathrm{mg} / \mathrm{kg}$ was found to cause damage to rat liver cells [61] and to result in an increase of liver enzymes [66]. It is noteworthy that the smaller dose of $0.2 \mathrm{mg} / \mathrm{kg}$ of sanguinarine had no toxic effect even when applied intraperitoneally, suggesting dose-dependency of liver toxicity of celandine alkaloids [61]. An in vitro study in HepG2 liver cells combining metabolomic with gene expression analyses revealed that neither the activated genes nor the proliferation response could be clearly related to the differing alkaloid content of different Chelidonium extracts. This emphasizes the importance of the manufacturing process for the toxicity of the preparation [67]. For the combination product STW5, containing Chelidonium majus extract in a low concentration, toxicological studies utilizing even high doses did not provide evidence for any appreciable toxicity. Nevertheless, 1 case with a positive temporal relationship between exposure to STW5 and hepatic toxicity was recently published [68]. The authors suspected a probable causal relationship to STW5 based upon the chronological association and the assumption that one of the ingredients (greater celandine) was potentially could have caused a drug-induced liver injury and the available information regarding the chronological exposure. On the other hand, the patient had also used before alprazolam, domperidone, paracetamol, and another homoeopathic complex preparation, some of which also can cause acute liver failure. While an ad-

Regulatory Approaches for Herbal Medicines in FGID verse effect of a medication never can be fully ruled out, appropriate post-marketing monitoring of adverse events related to the use of a specific medication is probably an important measure to ensure that a given product can be safely used and safety signals are appropriately monitored and analyzed instead of relying more or less random reporting of suspected adverse events that might be distorted by reporting bias. While case reports might be valuable if no other information is available, the information derived from case reports must be, whenever possible, analyzed in the context of complete pharmacovigilance data.

One population-based study from France revealed that the crude annual incidence of drug-induced liver injury was $13.9 \pm 2.4$ per 100,000 inhabitants; corresponding to standardized annual global rate of $8.1 \pm 1.5$ per 100,000 [69] while a similar study from Iceland reported a curde rate of 19.1 cases per 100,000 inhabitants [70]. Interestingly, drug-induced liver injury occurred in 1 of 2,350 treated with amoxicillin-clavulanate or 1 of 9,480 patients taking diclofenac. In this context, it is important to note that the prevalence of metabolic (obesity related) liver disease is increasing [71] and may increase the susceptibility to liver toxicity if drugs with a hepatotoxic potential are used [72].

\section{Adverse Event Pattern of Herbal Medicines}

With respect to the general adverse event pattern of herbal medications, 1 study evaluated adverse effects reported in randomized controlled trials [73]. The authors identified 111 studies of a single herb and 133 of multiple herbs that included in total 15,441 participants (male = 5,590 ; female $=9,851 ; 7,383$ for single and 8,058 for multiple herb studies). Overall, 480 cases (3.1\%) of adverse events (344 for single, 136 for multiple herb studies; $p<$ $0.01)$ were recorded. The most frequently reported adverse event was digestive symptoms (44.3\%), followed by adverse events such as loss of appetite. Based upon this, the authors concluded that herbal treatments appear "relatively" safe [73]. This conclusion was supported by a further systematic review [74] that searched 5 electronic databases to identify adverse effects of herbal medicines. While serious adverse events had been recorded, most of the herbal medicines evaluated in these studies were associated with only moderately severe or minor adverse effects [74]. Indeed, some herbal medications such as STW5 have been widely used for decades. It is estimated that during a time-span of 5 decades, approxi- 
mately $80,000,000$ patients have been treated with this preparation [55]. In spite of the widespread use and safety monitoring requirements that are in many jurisdictions identical to chemically defined medications, only very few cases of adverse events have been observed and reported [75] and very recently a 2 cases of a liver failure after treatment with STW5 has been reported $[68,76]$. In these 2 cases, causality was supported by a positive Roussel Uclaf Causality Assessment Method score [77] that suggested a highly probable link. In addition, in 1 case [76] the authors used monocyte-derived hepatocyte-like cells to test the medications the patients had used prior to the manifestation of the liver failure and the patient's cells responded with a release of liver enzymes after exposure to STW5. While this test is not independently validated (and some of the authors are involved in the commercialization of this tests), it is not unreasonable to assume that in this patients a very rare idiosyncratic drug-induced liver failure may have occurred. Considering the available data, this must be considered an exceptional rare event. Indeed, in the United States every year, approximately 2,000-3,000 Americans are affected by acute liver failure [78]. While drug-induced liver hepatoxicity accounted for 270 liver transplants from 1990 to 2002 in the United States [79], only 5\% were potentially related to herbal medicines. Paracetamol alone accounted for $45 \%$ of all liver failures that required liver transplantation. Similarly, based on recent data from the Spanish databases on drug-induced liver failure [80], 4\% of cases were related to herbal and dietary supplements and recently data from the United States were published that reported 899 cases of definite, highly likely, or probable drug induced liver injury. In this case series, all herbals and dietary complements together were related to only $16 \%$ of observed cases of drug-induced liver injury [81]. Thus, $84 \%$ were related to the chemically defined medicines. On the other hand, a report from Switzerland documented 10 cases of hepatotoxicity over a 7-year period related to one product line (Herbalife) [82]. This may suggest that some herbal products are hepatotoxic and subsequently specific preparations available to consumers carry a higher risk.

In nearly $50 \%$ of suspected cases of drug-induced liver toxicity, the liver abnormality is not caused by a medication [83], and when a medication was identified as the cause, paracetamol was the culprit in $70 \%$ of the reports. Of the remaining cases, only very few were in fact attributed to herbal medicinal preparations after formal causality assessment $[83,84]$. Interestingly, in substantial proportions of patients, the cause of the liv- er failure cannot be determined. Hadem et al. [85] reported for Germany that in $24 \%$ of cases the cause could not be determined, and Ichai and Samuel [86] have reported that between 16 and $44 \%$ of liver failures are of unknown origin. Considering the high rate of herbal use in many countries, it is very likely that some patients with acute liver failure may have had by chance exposure to herbal medicines. Thus, a temporal association neither proves nor rules out a causal relationship. Thus, while it is critical to avoid unnecessary risk exposures of patients, a causal relationship is only likely, if there is also a signal from the ongoing pharmacovigilance monitoring. The same holds true for traditional Chinese medicine [87].

\section{Balancing Risks and Benefits and the Use of Herbal Medicines in FGID}

The use of any therapeutic intervention (and subsequently regulatory approval of any therapy) ideally should include a careful risk-to-benefit appraisal. In FGID, it could be argued that - while substantially impacting on quality of life - there is no mortality associated with these disorders. Thus, all treatments are required to be without any risks, or the risk should be minimal. It is (very) obvious that many patients suffering from disorders summarized under the umbrella of FGID experience a substantial impact upon their quality of life. This beyond doubt may justify some risk exposure. In addition, it is evident that patients with FGID are characterized by excess health-care utilization. The excess health-care utilization is a reflection of the failure of many of the available treatments to cure or even appropriately control symptoms in a large proportion of patients. However, excess utilization of diagnostic and therapeutic interventions expose(s) these patients to an appreciable risk. Even for relatively safe diagnostic endoscopic procedures, the risk is not zero and in one large series $0.026 \%$ of procedures fatal outcomes were observed [38]. Thus, while the risk of the diagnostic measure is low, it is certainly not zero.

Comparisons of the risk-benefit profile of different therapeutic measures are typically not part of the drug authorization process. The original question during marketing authorization is whether a drug is efficacious and whether its inherent risks do not exceed its expected benefits. However, alternative treatments of FGID and their related risks should be taken into account as well. For instance, there are limited but statistically significant 
benefits of eluxadoline when compared to placebo in patients with IBS of the diarrhea type. This observed benefit must be weighed against the observed adverse events, such as pancreatitis in $0.3 \%$ of patients [88]. Other drugs such as prokinetics metoclopramide and domperidone, frequently used for FD, have already been restricted in their indications because of severe dyskinesias. For some herbals such as STW5, comprehensive documentation is available addressing different targets important for the treatment of functional GI diseases [50]. Clinical trials suggest efficacy in relation to FGID symptoms [54] and confirmed safety from toxicological studies as well as from randomized clinical trials and post-marketing surveys [89]. Thus, while the exposure of patients with a nonlife-threatening condition needs to be minimized, there are appropriate ways to achieve this and for some of the herbal preparations the available data are far more robust as compared to products that have been introduced only recently after clinical trials with at best several thousand study patients. On the other hand, it is impossible to exclude that very rare idiosyncratic drug-induced liver injuries occur even after treatment with medications that are considered safe [90] and recent data indicate that even after treatment with green tea extract in a placebo-controlled trial elevations in serum alanine aminotransferase levels occurred in $6.7 \%$ of recipients as compared with $0.7 \%$ of controls [91]. Thus, it is important to monitor the safety of herbal therapies appropriately to ensure that these treatments are appropriately used.

\section{Conclusions}

FGIDs are highly prevalent disorders with substantial impact on patients and society. There is currently no cure available, and most treatments improve symptoms only temporarily in a proportion of patients. Virtually all treatments including all pharmacotherapies or even diets can cause adverse outcomes, it is important to recognize that the most important driver for adverse outcomes in FGID patients is the failure to improve symptoms. Chronic symptoms drive health-care utilization as reflected by an excess use of diagnostic and therapeutic interventions, and this exposes patients to adverse outcomes from diagnostic tests or even unnecessary surgeries. The variety of underlying mechanisms causing symptoms may be addressed by a trial-and-error approach or a multitargeted treatment strategy that aims to address different mechanisms of action. Some herbal medicinal products meet

Regulatory Approaches for Herbal

Medicines in FGID this requirement due to their complex composition; the use of herbal therapies may be supported by data from clinical trials demonstrating efficacy and assessments of toxicologic properties that provide reassurance that treatments are safe [23]. Beside this, the strongest support for drug safety comes from appropriate pharmacovigilance. If large cohorts of patients have been exposed over time to the respective treatment, it is highly likely that all relevant adverse effects have become apparent.

Considering the widespread use of herbal medicines, and an appreciable background incidence of potential adverse events (e.g., acute liver failures), it is important to take into consideration that adverse events may be observed even if there is no causal relationship. A standardized approach is required to monitor and evaluate adverse events in patient cohorts and compare their incidence with the background incidence. The diagnosis of an adverse drug reaction and the determination of a causal relationship to a specific drug can be a complex task and even if diagnostic criteria for adverse drug reactions are rigorously applied is not without limitations [92]. Another issue might be reporting bias [93] and attitudes of clinicians may unconsciously influence the reporting of adverse events. Rigorous research methodologies using large population-based health databases should help do address some of these limitations [94]. Data linkage of medication data and the onset of specific predefined clinical events supported by large integrate electronic medical records [95] should enable clinicians and regulators to identify potential adverse events without clinical reporting bias. While patient safety is paramount, a comprehensive risk-benefit analysis that balances the risk exposure related (i.e., rate of relevant adverse events), and the potential benefits of the treatment that includes the efficacy with regard to the indication but also potential risk reduction in relation to diminished utilization of alternative treatments or diagnostic measures.

Both the use of chemically defined treatments as well as herbal therapies can be associated with adverse outcomes. Thus, similar to chemically defined therapies, appropriate toxicological studies exploring the safety of ingredients used for the preparation of herbal medicinal products, quality assurance in relating to the raw materials, and the production process as well as comprehensive post-marketing pharmacovigilance are required to minimize risks to patients. While these standards can be defined in accordance with standards for chemically defined treatments (Table 1), the complexity of the plant extracts needs to be appropriately taken into consideration. On the other hand, an approach that aims for a 
Table 1. Proposed quality framework for herbal medicines in FGID

\begin{tabular}{ll}
\hline Domain & Measure \\
\hline Safety & Appropriate toxicologic assessment of the plant extracts is done; doses tested should provide a \\
& enough safety margin (e.g., doses $>100$-fold higher compared to clinically used doses). \\
- & Quality assurance of raw materials: \\
a) Concentrations of active ingredients and/or lead substances are monitored in raw materials to \\
enable adjustments of production process to ensure consistent product qualities and \\
concentration of active ingredients in the marked product; \\
b) Monitoring of potential contaminations (e.g., heavy metals, mould) \\
- Appropriate pharmacovigilance of products used in the routine clinical setting consistent with the \\
procedures in place for chemically defined treatment \\
- In vivo and in vitro studies to explore mechanisms of action of the plant extracts in isolation and \\
in combination \\
- State-of-the-art clinical trials to proof efficacy regard to relevant outcome parameters \\
(symptom reduction, improvement of QoL) paired with studies on mechanisms \\
- Formal registration that mirrors chemically defined products for the respective jurisdictions \\
\hline Registration, market access \\
\hline FGID, functional gastrointestinal disorders; QoL, quality of life. \\
\hline
\end{tabular}

"zero harm" may expose patients to avoidable risks since in FGID patient's failure to control symptoms will result in increased utilization of potentially harmful diagnostic or therapeutic modalities.

Virtually all drugs and medications - including all herbal therapies - carry a risk of adverse events. The risks associated with the use of herbal medicines should be systematically mitigated by appropriate toxicological assessment of ingredients and production including the sourcing of raw materials monitored according to Good Manufacturing Practices. In addition, the use of herbal medicinal products should be scrutinized in an appropriate pharmacovigilance system. Ultimately, herbal therapies should meet the same regulatory and safety requirements as chemically defined treatments and preference should be given to herbal therapies that meet these requirements.

\section{Acknowledgments}

None.

\section{Disclosure Statement}

The manuscript summarizes the results of a workshop on the contemporary use of herbal medicines that took place in Frankfurt in May 2018. This educational event received unrestricted educational support from BAYER. G.H. received travel support from Bayer and is involved in clinical trials sponsored by Bayer, Takeda, Abbott, Celgene, Roche, Genetech, Lilly, Gilead, and ImmusanT. G.U.-M. received speaker's honoraria and travel support from Bayer and research grants from Bayer and Novartis. D.S., A.M., H.D.A., F.M., D.L., and P.M. received speaker honoraria and travel support from Bayer.

\section{Funding Sources}

No external funding.

\section{Author Contributions}

G.H. and P.M.: review idea, concept and design, drafting of the manuscript. D.S., A.M., H.D.A., G.U.-M, F.M., and D.L.: drafting of the manuscript, review of final manuscript.

\section{References}

1 Boyce PM, Talley NJ, Burke C, Koloski NA. Epidemiology of the functional gastrointestinal disorders diagnosed according to Rome II criteria: an Australian populationbased study. Intern Med J. 2006 Jan;36(1): 28-36.
2 Holtmann GJ, Ford AC, Talley NJ. Pathophysiology of irritable bowel syndrome. Lancet Gastroenterol Hepatol. 2016 Oct;1(2): 133-46.

3 Koloski NA, Talley NJ, Boyce PM. Epidemiology and health care seeking in the functional
GI disorders: a population-based study. Am J Gastroenterol. 2002 Sep;97(9):2290-9.

4 Thompson WG, Heaton KW, Smyth GT, Smyth C. Irritable bowel syndrome in general practice: prevalence, characteristics, and referral. Gut. 2000 Jan;46(1):78-82. 
5 Kheir A, Koloski N, Holtmann G, Walker M, Veysey M, Talley N. What keeps gastroenterologists in the public sector busy? A prospective one month snapshot audit. J Gastroenterol Hepatol. 2015;30:19.

6 Drossman DA, Hasler WL. Rome IV-Functional GI Disorders: Disorders of Gut-Brain Interaction. Gastroenterology. 2016 May; 150(6):1257-61.

7 Talley NJ, Holtmann G, Walker MM. Therapeutic strategies for functional dyspepsia and irritable bowel syndrome based on pathophysiology. J Gastroenterol. 2015 Jun;50(6): 601-13.

8 Chey WD, Maneerattaporn M, Saad R. Pharmacologic and complementary and alternative medicine therapies for irritable bowel syndrome. Gut Liver. 2011 Sep;5(3): 253-66.

9 Liebregts T, Adam B, Bredack C, Röth A, Heinzel S, Lester S, et al. Immune activation in patients with irritable bowel syndrome. Gastroenterology. 2007 Mar;132(3):913-20.

10 Holtmann G, Talley NJ. Functional dyspepsia. Curr Opin Gastroenterol. 2015 Nov; 31(6):492-8.

11 Holtmann G, Shah A, Morrison M. Pathophysiology of Functional Gastrointestinal Disorders: A Holistic Overview. Dig Dis. 2017;35 Suppl 1:5-13.

12 Jones MP, Tack J, Van Oudenhove L, Walker MM, Holtmann G, Koloski NA, et al. Mood and Anxiety Disorders Precede Development of Functional Gastrointestinal Disorders in Patients but Not in the Population. Clin Gastroenterol Hepatol. 2017 Jul;15(7):1014-20. e4.

13 Choi YJ, Kim N, Yoon H, Shin CM, Park YS, Kim JW, et al. Overlap between irritable bowel syndrome and functional dyspepsia including subtype analyses. J Gastroenterol Hepatol. 2017 Sep;32(9):1553-61.

14 Perveen I, Rahman MM, Saha M, Rahman MM, Hasan MQ. Prevalence of irritable bowel syndrome and functional dyspepsia, overlapping symptoms, and associated factors in a general population of Bangladesh. Indian J Gastroenterol. 2014 May;33(3):26573.

15 Futagami S, Yamawaki H, Shimpuku M, Izumi N, Wakabayashi T, Kodaka Y, et al.; Journal of Nippon Medical School =. Impact of coexisting irritable bowel syndrome and nonerosive reflux disease on postprandial abdominal fullness and sleep disorders in functional dyspepsia. J Nippon Med Sch. 2013;80(5): $362-70$.

16 Mearin F, Pérez-Oliveras M, Perelló A, Vinyet J, Ibañez A, Coderch J, et al. Dyspepsia and irritable bowel syndrome after a Salmonella gastroenteritis outbreak: one-year follow-up cohort study. Gastroenterology. 2005 Jul; 129(1):98-104

17 von Wulffen M, McMaster J, Rich G, Koloski N, Talley NJ, Holtmann G. Overlap of Irritable Bowel Syndrome and Functional Dyspepsia in the Clinical Setting: Prevalence and
Risk Factors. Dig Dis Sci. 2019 Feb;64(2): 480-86.

18 Mapel DW. Functional disorders of the gastrointestinal tract: cost effectiveness review. Best Pract Res Clin Gastroenterol. 2013 Dec; 27(6):913-31.

19 Burbige EJ. Irritable bowel syndrome: diagnostic approaches in clinical practice. Clin Exp Gastroenterol. 2010;3:127-37.

20 Moayyedi P, Lacy BE, Andrews CN, Enns RA, Howden CW, Vakil N. ACG and CAG Clinical Guideline: management of Dyspepsia. Am J Gastroenterol. 2017 Jul;112(7):988-1013.

21 Layer P, Andresen V, Pehl C, Allescher H, Bischoff SC, Classen M, et al.; Deutschen Gesellschaft für Neurogastroenterologie und Motilität. [Irritable bowel syndrome: german consensus guidelines on definition, pathophysiology and management]. Z Gastroenterol. 2011 Feb;49(2):237-93.

22 Bensoussan A, Talley NJ, Hing M, Menzies R, Guo A, Ngu M. Treatment of irritable bowel syndrome with Chinese herbal medicine: a randomized controlled trial. JAMA. 1998 Nov;280(18):1585-9.

23 Holtmann G, Talley NJ. Herbal medicines for the treatment of functional and inflammatory bowel disorders. Clin Gastroenterol Hepatol. 2015 Mar;13(3):422-32.

24 Madisch A, Holtmann G, Plein K, Hotz J. Treatment of irritable bowel syndrome with herbal preparations: results of a double-blind, randomized, placebo-controlled, multi-centre trial. Aliment Pharmacol Ther. 2004 Feb; 19(3):271-9.

25 Madisch A, Holtmann G, Mayr G, Vinson B, Hotz J. Treatment of functional dyspepsia with a herbal preparation. A double-blind, randomized, placebo-controlled, multicenter trial. Digestion. 2004;69(1):45-52.

26 von Arnim U, Peitz U, Vinson B, Gundermann KJ, Malfertheiner P. STW 5, a phytopharmacon for patients with functional dyspepsia: results of a multicenter, placebo-controlled double-blind study. Am J Gastroenterol. 2007 Jun; 102(6):1268-75.

27 Alammar N, Wang L, Saberi B, Nanavati J, Holtmann G, Shinohara RT, et al. The impact of peppermint oil on the irritable bowel syndrome: a meta-analysis of the pooled clinical data. BMC Complement Altern Med. 2019 Jan;19(1):21.

28 Rich G, Shah A, Koloski N, Funk P, Stracke B, Köhler S, et al. A randomized placebo-controlled trial on the effects of Menthacarin, a proprietary peppermint- and caraway-oilpreparation, on symptoms and quality of life in patients with functional dyspepsia. Neurogastroenterol Motil. 2017 Nov;29(11):e13132.

29 Koloski NA, Talley NJ, Huskic SS, Boyce PM. Predictors of conventional and alternative health care seeking for irritable bowel syndrome and functional dyspepsia. Aliment Pharmacol Ther. 2003 Mar;17(6):841-51.

30 Burgmann T, Rawsthorne P, Bernstein CN. Predictors of alternative and complementary medicine use in inflammatory bowel disease: do measures of conventional health care utilization relate to use? Am J Gastroenterol. 2004 May;99(5):889-93.

31 Peery AF, Dellon ES, Lund J, Crockett SD, McGowan CE, Bulsiewicz WJ, et al. Burden of gastrointestinal disease in the United States: 2012 update. Gastroenterology. 2012 Nov; 143(5):1179-1187.e3.

32 Vu J, Kushnir V, Cassell B, Gyawali CP, Sayuk GS. The impact of psychiatric and extraintestinal comorbidity on quality of life and bowel symptom burden in functional GI disorders. Neurogastroenterol Motil. 2014 Sep;26(9): 1323-32.

33 Cash BD, Sullivan D, Barghout V. Total costs of IBS: employer and managed care perspective. Am J Manag Care.2005 Apr;11(1 Suppl):S7-16.

34 Buono JL, Carson RT, Flores NM. Health-related quality of life, work productivity, and indirect costs among patients with irritable bowel syndrome with diarrhea. Health Qual Life Outcomes. 2017 Feb;15(1):35.

35 Buono JL, Mathur K, Averitt AJ, Andrae DA. Economic Burden of Irritable Bowel Syndrome with Diarrhea: Retrospective Analysis of a U.S. Commercially Insured Population. J Manag Care Spec Pharm. 2017 Apr;23(4): 453-60.

36 Leffler DA, Kheraj R, Garud S, Neeman N, Nathanson LA, Kelly CP, et al. The incidence and cost of unexpected hospital use after scheduled outpatient endoscopy. Arch Intern Med. 2010 Oct;170(19):1752-7.

37 Park HM, Kim ES, Lee SM, Lee YJ, Park KS, Cho KB, et al. Clinical Characteristics and Mortality of Life-Threatening Events Requiring Cardiopulmonary Resuscitation in Gastrointestinal Endoscopy Units. Medicine (Baltimore). 2015 Oct;94(43):e1934.

38 Hagel AF, Boxberger F, Dauth W, Kessler HP, Neurath MF, Raithel M. Colonoscopy-associated perforation: a 7-year survey of in-hospital frequency, treatment and outcome in a German university hospital. Colorectal Dis. 2012 Sep;14(9):1121-5.

39 McCollough CH, Bushberg JT, Fletcher JG Eckel LJ. Answers to Common Questions About the Use and Safety of CT Scans. Mayo Clin Proc. 2015 Oct;90(10):1380-92.

40 Longstreth GF, Yao JF. Irritable bowel syndrome and surgery: a multivariable analysis. Gastroenterology. 2004 Jun;126(7):1665-73.

41 Kirk G, Kennedy R, McKie L, Diamond T, Clements B. Preoperative symptoms of irritable bowel syndrome predict poor outcome after laparoscopic cholecystectomy. Surg Endosc. 2011 Oct;25(10):3379-84.

42 Malfertheiner P, Megraud F, O'Morain CA, Atherton J, Axon AT, Bazzoli F, et al.; European Helicobacter Study Group. Management of Helicobacter pylori infection - the Maastricht IV/ Florence Consensus Report. Gut. 2012 May;61(5):646-64.

43 Craig OF, Quigley EM. Current and emerging therapies for the management of functional gastrointestinal disorders. Ther Adv Chronic Dis. 2011 Mar;2(2):87-99.
Regulatory Approaches for Herbal Medicines in FGID 
44 Dionne J, Ford AC, Yuan Y, Chey WD, Lacy BE, Saito YA, et al. A Systematic Review and Meta-Analysis Evaluating the Efficacy of a Gluten-Free Diet and a Low FODMAPs Diet in Treating Symptoms of Irritable Bowel Syndrome. Am J Gastroenterol. 2018 Sep;113(9): 1290-300

45 Laird KT, Tanner-Smith EE, Russell AC, Hollon SD, Walker LS. Short-term and Longterm Efficacy of Psychological Therapies for Irritable Bowel Syndrome: A Systematic Review and Meta-analysis. Clin Gastroenterol Hepatol. 2016 Jul;14(7):937-947.e4.

46 Hohenester B, Rühl A, Kelber O, Schemann $\mathrm{M}$. The herbal preparation STW5 (lberogast) has potent and region-specific effects on gastric motility. Neurogastroenterol Motil. 2004 Dec;16(6):765-73.

47 Storr M, Sibaev A, Weiser D, Kelber O, Schirra J, Goke B, et al. Herbal extracts modulate the amplitude and frequency of slow waves in circular smooth muscle of mouse small intestine. Digestion. 2004;70(4):257-64.

48 Wadie W, Abdel-Aziz H, Zaki HF, Kelber O, Weiser D, Khayyal MT. STW 5 is effective in dextran sulfate sodium-induced colitis in rats. Int J Colorectal Dis. 2012 Nov;27(11):1445-53.

49 Kelber O, Bauer R, Kubelka W. Phytotherapy in Functional Gastrointestinal Disorders. Dig Dis. 2017;35 Suppl 1:36-42.

50 Allescher HD, Abdel-Aziz H. Mechanism of Action of STW 5 in Functional Dyspepsia and IBS: The Origin of Multi-Target. Dig Dis. 2017;35 Suppl 1:18-24.

51 Sakharkar P. Lead Poisoning Due to Herbal Medications. Indian J Clin Biochem. 2017 Oct;32(4):500-1.

52 US Food and Drug Administration. [Accessed January 22]. Available from: http:// www.gpo.gov/fdsys/BILLS-103s784es/pdf/ BILLS103s784es/pdf.

53 Abdel-Aziz H, Kelber O, Lorkowski G, Storr M. Evaluating the Multitarget Effects of Combinations through Multistep Clustering of Pharmacological Data: the Example of the Commercial Preparation Iberogast. Planta Med. 2017 Oct;83(14-15):1130-40.

54 Malfertheiner P. STW 5 (Iberogast) Therapy in Gastrointestinal Functional Disorders. Dig Dis. 2017;35 Suppl 1:25-9.

55 Ottillinger B, Storr $\mathrm{M}$, Malfertheiner $\mathrm{P}$, Allescher HD. STW 5 (Iberogast $^{\circledR}$ ) - a safe and effective standard in the treatment of functional gastrointestinal disorders. Wien Med Wochenschr. 2013 Feb;163(3-4):65-72.

56 Psotová J, Klejdus B, Vecera R, Kosina $\mathrm{P}$ Kubán V, Vicar J, et al. A liquid chromatographic-mass spectrometric evidence of dihydrosanguinarine as a first metabolite of sanguinarine transformation in rat. J Chromatogr B Analyt Technol Biomed Life Sci. 2006 Jan;830(1):165-72.

57 Psotova J, Vecera R, Zdarilova A, Anzenbacherova E, Kosina P, Svobodova A, et al. Safety assessment of sanguiritrin, alkaloid fraction of Macleaya cordata, in rats. Vet Med Czech. 2006;51:144-55.
58 Kosina P, Walterová D, Ulrichová J, Lichnovský V, Stiborová M, Rýdlová $\mathrm{H}$, et al. Sanguinarine and chelerythrine: assessment of safety on pigs in ninety days feeding experiment. Food Chem Toxicol. 2004 Jan; 42(1):85-91.

59 Walterová D, Ulrichová, Preininger V, Simánek V, Lenfeld J, Lasovský J. Inhibition of liver alanine aminotransferase activity by some benzophenanthridine alkaloids. J Med Chem. 1981 Sep;24(9):1100-3.

60 Wolff J, Knipling L. Antimicrotubule properties of benzophenanthridine alkaloids. Biochemistry. 1993 Dec;32(48):13334-9.

61 Ulrichova J, Walterova D, Vavreckova C, Kamarad V, Simanek V. Cytotoxicity of benzo[c] phenantridium alkaloids in isolated rat hepatocytes. Phytother Res. 1996;10(3):220-3.

62 Wang BH, Lu ZX, Polya GM. Inhibition of eukaryote protein kinases by isoquinoline and oxazine alkaloids. Planta Med. 1997 Dec; 63(6):494-8.

$63 \mathrm{Hu} \mathrm{CM}$, Cheng HW, Cheng YW, Kang JJ. Induction of skeletal muscle contracture and calcium release from isolated sarcoplasmic reticulum vesicles by sanguinarine. Br J Pharmacol. 2000 May;130(2):299-306.

64 Panzer A, Joubert AM, Bianchi PC, Hamel E, Seegers JC. The effects of chelidonine on tubulin polymerisation, cell cycle progression and selected signal transmission pathways. Eur J Cell Biol. 2001 Jan;80(1):111-8.

65 Debiton E, Madelmont JC, Legault J, Barthomeuf C. Sanguinarine-induced apoptosis is associated with an early and severe cellular glutathione depletion. Cancer Chemother Pharmacol. 2003 Jun;51(6):474-82.

66 Dalvi RR. Sanguinarine: its potential as a liver toxic alkaloid present in the seeds of Argemone mexicana. Experientia. 1985 Jan;41(1):77-8.

67 Orland A, Knapp K, König GM, Ulrich-Merzenich G, Knöß W. Combining metabolomic analysis and microarray gene expression analysis in the characterization of the medicinal plant Chelidonium majus L. Phytomedicine. 2014 Oct;21(12):1587-96.

68 Sáez-González E, Conde I, Díaz-Jaime FC Benlloch S, Prieto M, Berenguer M. IberogastInduced Severe Hepatotoxicity Leading to Liver Transplantation. Am J Gastroenterol. 2016 Sep;111(9):1364-5.

69 Sgro C, Clinard F, Ouazir K, Chanay H, Allard $\mathrm{C}$, Guilleminet $\mathrm{C}$, et al. Incidence of drug-induced hepatic injuries: a French populationbased study. Hepatology. 2002 Aug;36(2): 451-5.

70 Bjornsson ES, Bergmann OM, Bjornsson HK, Kvaran RB, Olafsson S. Incidence, presentation, and outcomes in patients with drug-induced liver injury in the general population of Iceland. Gastroenterology. 2013 Jun; 144(7): 1419-25.e1-3.

71 Bellentani S. The epidemiology of non-alcoholic fatty liver disease. Liver Int. 2017 Jan;37 Suppl 1:81-4.

72 Wree A, Broderick L, Canbay A, Hoffman $\mathrm{HM}$, Feldstein AE. From NAFLD to NASH to cirrhosis-new insights into disease mechanisms. Nat Rev Gastroenterol Hepatol. 2013 Nov; 10(11):627-36.

73 Lee JY, Jun SA, Hong SS, Ahn YC, Lee DS, Son CG. Systematic Review of Adverse Effects from Herbal Drugs Reported in Randomized Controlled Trials. Phytother Res. 2016 Sep; 30(9):1412-9.

74 Posadzki P, Watson LK, Ernst E. Adverse effects of herbal medicines: an overview of systematic reviews. Clin Med (Lond). $2013 \mathrm{Feb}$ 13(1):7-12.

75 Malfertheiner P. STW 5 (Iberogast) Therapy in Gastrointestinal Functional Disorders. Dig Dis. 2017;35 Suppl 1:25-29.

76 Gerhardt F, Benesic A, Tillmann HL, Rademacher S, Wittekind $\mathrm{C}$, Gerbes $\mathrm{AL}$, et al. Iberogast-Induced Acute Liver Failure-Reexposure and In Vitro Assay Support Causality. Am J Gastroenterol. 2019 Aug;114(8):1358-

77 Danan G, Teschke R. Roussel Uclaf Causality Assessment Method for Drug-Induced Liver Injury: present and Future. Front Pharmacol. 2019 Jul;10:853.

78 Hoofnagle JH, Carithers RL Jr, Shapiro C, Ascher N. Fulminant hepatic failure: summary of a workshop. Hepatology. 1995 Jan;21(1) $240-52$.

79 Russo MW, Galanko JA, Shrestha R, Fried MW, Watkins P. Liver transplantation for acute liver failure from drug induced liver injury in the United States. Liver Transpl. 2004 Aug;10(8):1018-23.

80 Medina-Caliz I, Garcia-Cortes M, GonzalezJimenez A, Cabello MR, Robles-Diaz M, Sanabria-Cabrera J, et al. Herbal and Dietary Supplement-Induced Liver Injuries in the Spanish DILI Registry. Clin Gastroenterol Hepatol. 2018 Sep;16(9):1495-502.

81 Chalasani N, Bonkovsky HL, Fontana R, Lee W, Stolz A, Talwalkar J, et al.; United States Drug Induced Liver Injury Network. Features and Outcomes of 899 Patients With Drug-Induced Liver Injury: The DILIN Prospective Study. Gastroenterology. 2015 Jun;148(7): 1340-52.e7.

82 Schoepfer AM, Engel A, Fattinger K, Marbet UA, Criblez D, Reichen J, et al. Herbal does not mean innocuous: ten cases of severe hepatotoxicity associated with dietary supplements from Herbalife products. J Hepatol. 2007 Oct;47(4):521-6.

83 Brown AC. Liver toxicity related to herbs and dietary supplements: Online table of case reports. Part 2 of 5 series. Food Chem Toxicol. 2017;107(Pt A):472-501.

84 Teschke R, Schulze J, Schwarzenboeck A, Eickhoff A, Frenzel C. Herbal hepatotoxicity: suspected cases assessed for alternative causes. Eur J Gastroenterol Hepatol. 2013 Sep; 25(9):1093-8.

85 Hadem J, Tacke F, Bruns T, Langgartner J, Strnad P, Denk GU, et al. Etiologies and outcomes of acute liver failure in Germany. Clin Gastroenterol Hepatol. 2012 Jun;10(6):6649.e2. 
86 Ichai P, Samuel D. Epidemiology of liver failure. Clin Res Hepatol Gastroenterol. 2011 Oct;35(10):610-7.

87 Teschke R, Wolff A, Frenzel C, Schulze J. Review article: herbal hepatotoxicity-an update on traditional Chinese medicine preparations. Aliment Pharmacol Ther. 2014 Jul; 40(1):32-50.

88 Lembo AJ, Lacy BE, Zuckerman MJ, Schey R, Dove LS, Andrae DA, et al. Eluxadoline for Irritable Bowel Syndrome with Diarrhea. N Engl J Med. 2016 Jan;374(3):242-53.

89 Lapina TL, Trukhmanov AS. Herbal Preparation STW 5 for Functional Gastrointestinal Disorders: Clinical Experience in Everyday Practice. Dig Dis. 2017;35 Suppl 1:30-5.
90 Hoofnagle JH, Björnsson ES. Drug-Induced Liver Injury - Types and Phenotypes. N Engl J Med. 2019 Jul;381(3):264-73.

91 Dostal AM, Samavat H, Bedell S, Torkelson C, Wang R, Swenson K, et al. The safety of green tea extract supplementation in postmenopausal women at risk for breast cancer: results of the Minnesota Green Tea Trial. Food Chem Toxicol. 2015 Sep;83:26-35.

92 Naranjo CA. A clinical pharmacologic perspective on the detection and assessment of adverse drug reactions. Drug Inf J. 1986; 20(4):387-93.
93 Matsuda S, Aoki K, Kawamata T, Kimotsuki $\mathrm{T}$, Kobayashi $\mathrm{T}$, Kuriki $\mathrm{H}$, et al. Bias in spontaneous reporting of adverse drug reactions in Japan. PLoS One. 2015 May; 10(5):e0126413.

94 Chan EW, Liu KQ, Chui CS, Sing CW, Wong LY, Wong IC. Adverse drug reactions - examples of detection of rare events using databases. Br J Clin Pharmacol. 2015 Oct;80(4): $855-61$.

95 Scott IA, Pillans PI, Barras M, Morris C. Using EMR-enabled computerized decision support systems to reduce prescribing of potentially inappropriate medications: a narrative review. Ther Adv Drug Saf. 2018 Jul;9(9):55973. 